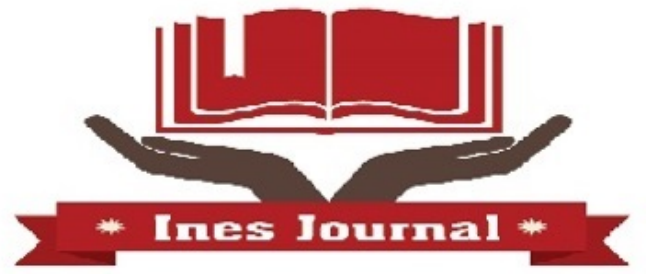

ISSN: 2149-0848

\section{INESJOURNAL}

ULUSLARARASI EĞİTIM BİLIMLERİ DERGİSİ THE JOURNAL OF INTERNATIONAL EDUCATION SCIENCE

Vahap ALBAYRAK ${ }^{1}$

\title{
BİR FLL JR. MACERASI; KIZ ÇOCUKLARININ STEM İLE BULUŞMASI
}

\author{
Kabul Tarihi: 15.01.2020 Yayın Tarihi: 31.03.2020
}

Künye (APA): Albayrak, V. (2020). Bir FLL jr. macerası; kız çocuklarının STEM ile buluşması. The Journal of International Education Science, 22 (7), 55-59. DOI:

\section{ÖZ}

Yeniköy İlkokulu Torbalı-IZMIR olarak tamamı kızlardan oluşan 4. Sınıf öğrencileriyle First Lego League Jr. Programına katıldık. Bu programa katılmamız Bilim Kahramanların Derneği sayesinde olmuştur. Özellikle kız öğrencilerden oluşan bir takım oluşturulması dernek tarafindan istenmiş ve kız öğrencilerin bilim, fen, mühendislik ve matematikle buluşturulması sağlanmıştır. Bu programı uygularken kız öğrencilerin STEM'e yaklaşımını, tasarım aşamasında karşılaştığımız sorunları, bu sorunları nasıl çözdüğümüzü ve rubriklerin tasarıma etkisi incelendi.12 oturum sonunda öğrenciler, Ay'da insanların yaşayabileceği bir Ay üssü inşa ettiler. Erken uyarı sisteminden, Ay'da madencilik yapmasına, buzullarının eritilmesinden, ekosistem oluşturularak tarım yapılmasına, güneş panellerinden, banyo için vakumlu küvete, droneların taşıma ve gözlem için kullanılabilir olmasına kadar yaratıcılıklarını ürüne çevirip prototip tasarladılar. Bu program kız öğrencilerin meslek seçimlerini ve kariyer planlarını da etkiledi. Önceden öğretmen, hemşire, kuaför olmak isteyen öğrenciler, fuarda aldıkları ödülden sonra fikirlerini değiştirdi. Astronot, drone pilotu ve mühendis olmak istediklerini ifade ettiler.

Anahtar Sözcükler: STEM, Kodlama, Yaratıcllık, Tasarım, Kız çocukları

\footnotetext{
${ }^{1}$ Öğretmen, MEB, walbayrock@gmail.com
} 


\section{ONE FLL JR. ADVENTURE; MEETING STEM WITH FEMALE STUDENTS}

\section{ABSTRACT}

As Yeniköy Elementary School, Torbalı /İzmir, we joined the First Lego League Jr. program with all 4th Grade female students. We participated in this program thanks to Bilim Kahramanları Derneği (The Association of Science Heroes). It was requested to form a team of female students by the association in particular and it was ensured that female students were introduced to science, engineering and mathematics. While implementing this program, it was examined that female students 'viewpoint, the problems we faced during the design phase, how we solved these problems and the effect of rubrics on the design. At the end of the 12 session, the students built a Moon base where people could live on the moon. They designed a prototype by developing their creativity on the early warning system, mining on the moon, melting the glaciers, cultivating by creating ecosystem, solar panels, vacuum tubes for bathrooms and the availability of drones for transport and observation. This program also affected career choices and plans of female students. Students who wanted to be Teachers, nurses and hairdressers change their ideas after the award they received at the fair. They wanted to be an astronaut, drone pilot and engineer.

Key words: Stem, Coding, Creativity, Design, Female students

\section{GíRiş}

Bilim Kahramanları Buluşuyor First Lego League Jr. Rekabetçi olmayan el becerisi gerektiren 6-10 yaş arası çocuklar için düzenlenen bir stem programıdır. En çok 6 kişiden oluşturulan takımlar 10-12 oturum boyunca sezon temasının gerektirdiği çalışmaları yapar. Daha sonra çalışmalarını fuarda sunar. Takımlar education keşif modeli ve LEGO parçalarıyla gerçek hayattan yola çıkarak sezon temasına uygun tasarımlar yapar. Lego education wedo2.0 setiyle de temel mühendislik ve kodlama becerisi öğrenirler.

Bu programa katılmamız Bilim Kahramanları Derneği, finansmanımız ise Kızlar Bilimle Buluşuyor sosyal sorumluluk projesi sayesinde olmuştur. Yeniköy İlkokulu Torbal1-IZZMíR olarak tamamı kızlardan oluşan 4. Sınıf öğrencileriyle First Lego League Jr. programına katılım sağlandı. Okulumuz toplam 60 öğrencili bir köy okuludur. Bu programa katılmak bizim gibi köy okulları için bir hayaldi. Bilim Kahramanları Derneği bu hayalinin gerçek olmasına vesile oldu. Bilim Kahramanları Derneği’ne bir kez daha teşekkür ediyorum.

Görev, yaşanılabilir bir Ay üssü inşa etmekti. Ay'a roket gemisi ile belli miktarda su, hava, enerji ve istenilen herhangi bir şeyi götürülebilirdi. Fakat bu götürülenlerinin sürdürebilirliğini nasıl sağlanabilirdi? Çözmesi gereken 4 temel problem vardır. Su, hava, enerji ve Ay'daki diğer sorunlar.

\section{YÖNTEM}

Her öğrenciye birer mühendislik defteri verildi. Sezon boyunca mühendislik defteri ile çalış1ld. Mühendislik defteri, öğrencilerin problemi keşfetmesine, problemi nasıl çözebileceğine ait fikirleri ve çizimleri ifade etmesine imkân veren bir materyaldi. Her öğrenci problemi çözeceğini düşündügü fikir ve tasarımları mühendislik defterine yazardı. Mühendislik defterindeki fikir ve çizimler takımca tartışılıp problemi çözecek olan tasarıma karar verilirdi. Mühendislik defterindeki 'gelecek oturum' bölümü bir sonraki oturumda çözülmesi istenen sorunu ifade ederdi. Öğrencilerden bu sorun hakkında araştırma yapması istenildi. Bu yöntemle öğrencilerin, gelecek oturumda kullanacağı bilgiye kendilerinin ulaşması amaçlandı. Öğrenciler yaptığı araştırmaları takım arkadaşlarıyla paylaşıp akran öğrenmesini gerçekleştirirdi. Ayrıca 
öğrencilerden Ay ile ilgili belgesel ve videolar izlemesi istendi. Bu yöntemle öğrencilerin Ay hakkında birçok bilgiye sahip olması amaçlandı.

Öğrenciler problemin çözümüne ilişkin fikir üretmekte biraz zorlandı. Arkadaşlarından birinin ürettiği fikri biraz değiştirip söylüyorlardı. Kısır döngüye düşüyorlardı. On iki oturumdan oluşan bu süreç hiç de kolay olmadı. Özellikler akademik anlamdaki sınıf birincisi çok zorlandı. Öğrencilerin yaşadığı bu sıkıntı çözebilmek için beyin firtınası yöntemini kullandı. Ortaya atılan fikirler üzerine tartışma yaptıkça ilerleme kaydedildi. Her oturum bu yöntem uygulandı.

\section{PROBLEMLER ICÇIN ÇÖZÜM ÖNERILERIMIZ}

\begin{tabular}{|c|c|}
\hline $\begin{array}{l}\text { HAVA } \\
\square \text { Ay yüzeyindeki toz ve gevşek taşlara } \\
\text { regolit denir. Regolitlerin içinde belli } \\
\text { miktarda hava olduğunu ve bundan } \\
\text { yararlanabileceği ifade edildi. } \\
\square \quad \text { Sera ile temiz -kirli hava döngüsünü } \\
\text { sağlanabilirdi. }\end{array}$ & $\begin{array}{l}\text { ENERJİ } \\
\square \quad \text { Enerji için güneş panellerinden } \\
\text { yararlanılmasına karar verildi. } \\
\square \quad \text { Ay'da } 14 \text { gün gece } 14 \text { gün gündüz } \\
\text { olduğunu ögrenildi. } \\
\square \quad \text { Bunun için çözüm aranıldı. }\end{array}$ \\
\hline $\begin{array}{l}\text { SU } \\
\square \quad \text { Öğrencilerce yapılan araştırma } \\
\text { sonucunda Ay'da buzulların olduğunu } \\
\text { öğrenildi. } \\
\text { Buzulları suya dönüştürmek için } \\
\text { fikirler ortaya atıldı. }\end{array}$ & $\begin{array}{l}\text { AYDAKİ DİĞER İHTIYACLARIMIZ? } \\
\square \text { Ay'da insanlarının aşağıdaki } \\
\text { ihtiyaçlarının olabileceği belirlendi. } \\
\square \text { Yemek pişirmek, oyun oynamak, } \\
\text { uyumak, iletişim, yürüyüş vb. } \\
\square \text { Bu problemlerin çözümü için fikirler } \\
\text { üretip tasarımlar yapıldı. }\end{array}$ \\
\hline
\end{tabular}

Çizilen tasarımlar da takımca tartış11ıyordu. Daha sonra birlikte karar verilip, LEGO SETİ kullanılarak ürün yapılıyordu. Eğer tasarımda hareketli, sesli, sensörlü parçalar varsa wedo 2.0 setinden eklenip kodlamaları yapılıyordu. Ortaya çıkan tasarım takımca test edilip artı ve eksilerine göre yeniden tasarlanıyordu.

\section{BULGULAR}

\section{1) Tasarım Geliştirme:}

$\mathrm{Bu}$ aşamada şu gözlemlendi, ortada bir ürün varsa öğrenciler yaratıcılıklarını kullanarak tasarımı geliştiriyor. Ortada herhangi bir ürün yokken ilkokul öğrencileri yaratıcı olmakta zorlanıyordu. Bu da ilkokul öğrencilerinin somut evrede olmasının sonucudur. Ortada var olan somut bir obje öğrencilerin yaratıcılıklarının ortaya çıkmasına katkı sağlıyordu. Bu noktada mühendislik defteri kullanılması çok büyük bir katkı sağlamıştır. Her oturum wedo 2.0 seti ile yapabilecek tasarımlar mevcuttu. Bu tasarımlar öğrencilere 1şık tutuyordu. Bu tasarım üzerine tartışıp geliştiriliyordu. Bazen de tartışmalar, ilk ürüne hiç benzemeyen bir ürüne götürüyordu.

Tasarım aşamasında öğrencilere sorular yöneltilmelidir. STEM uygulamaları yaparken ilkokul öğrencilerinden illaki yeni bir şeyler üretmesini beklenmemelidir. Var olan üzerinde ne gibi değişiklikler yapabiliriz? Nasıl amacımıza uygun bir ürün haline getirilebiliriz? Bu ürün hangi yönüyle amacımıza fayda sağlar veya sağlamaz? Gibi sorularla öğrencileri harekete geçirmeli ve yaratıcılıklarını ortaya çıkarmalıdır. Stem'deki tasarım aşaması, öğrencilerin yaratıcılık becerisinin gelişmesine büyük katkı sağlamaktadır. 


\section{2)Kız ve Erkek Öğrencilerin Yaklaşımı}

Sınıf mevcudu 13 olduğundan kız ve erkek öğrencilerin STEM'e olan ilgilerini belirlemek için 3 oturum birlikte çalışma yapıldı. Erkek öğrenciler Lego setine çok ilgiydi. Hemen Lego setiyle bir şeyler tasarlamaya başladılar. Kız öğrencilerle kodlama çalışması yapıldı. Kız öğrenciler, kodlamanın dijital olmasının ilgi çekici olduğunu ve kodlamayı severek yaptıkları ifade ettiler. $\mathrm{Bu}$ durum kız çocuklarının kodlamaya ilgili ve meraklı olduğunu, gerekli yönlendirmeler yapılırsa bu alanda başarılı olabilecekleri olgusunu ortaya çıkarmıştır.

\section{3)Rubriklerin Etkisi:}

Sezon boyunca rubrikler kullanıldı. Bu tasarlanacak ürünün sınırlarını çiziyor ve odak noktalarını belirliyordu. Rubrikler öğrencilere sınırları çizilmiş bir özgürlük alanı sağlamaktadır. $\mathrm{Bu}$ da öğrencinin problem ve amaçtan sapmasını engelliyordu. Önceden kriterler verildiği için öğrenciye süreç içinde ve süreç sonrasında öz değerlendirme yapma imkânı sunuyordu.

\section{SONUÇ VE TARTIŞMA}

12 oturum sonucunda Takımımız (Sabiha GÜRAYMAN) Ay'da insanların yaşayabileceği bir Ay üssü inşa ettiler. Sabiha GÜRAYMAN ülkemizin ilk $\underline{k} \boldsymbol{a d ı n}$ mühendisidir. Takımın tamamı kız öğrencilerden oluştuğu için öğrencilerden, ülkemizdeki başarılı işlere imza atmış kadın mühendislerimizin araştırması istendi. Bu araştırma görevi öğrencilere verilirken öğrencilerin motivasyonunun artırması ve öğrencilerin kariyer planlamasına 1şık tutması amaçlanmıştır. Öğrenciler yaptıkları araştırmaları arkadaşlarıyla paylaştı. Sabiha GÜRAYMAN hakkındaki araştırmalar öğrencileri daha çok etkiledi ve bu isme karar verildi.

\section{Yaşanabilir Ay Üssümüz}

- Erken uyarı sisteminden,

- Ay'da madencilik yapmasina,

- Ay'daki buzullarının eritilmesinden,

- Ekosistem oluşturularak tarım yapılmasına,

- Güneş panellerinden, banyo için vakumlu küvete,

- Droneların taşıma ve gözlem için kullanılabilir olmasına kadar yaratıcılıklarını ürüne çevirip prototipler tasarlandı.

\section{Bana Anlat Posteri!}

Yapılan çalışmalar bir poster ile fuarda misafirlere anlatılıyordu. Bu poster üç bölümden oluşuyor:

1. KEŞFET: Bu sezonda ne öğrendin? Nasıl öğrendin?

2. YARAT VE TEST ET: Ay Üssü'nüzü ve wedo 2.0 programını nasıl oluşturdunuz? Nasıl test ettiniz?

3. PAYLAŞ: Takım hakkında ne paylaşmak istersiniz?

gibi sorulara cevap veren bir poster sunum takımca oluşturuldu.

Poster sunum öğrencilerin iletişim, kendini ifade etme, ekip ruhu oluşturma gibi becerilerin gelişmesine katkı sağladı. 
Fuardan ödülle dönmeleri ve yaptıkları tasarımın başkaları tarafından takdir edilmesi, öğrencilerin başarabilirim duygusunun gelişmesini sağladı. Özgüvenlerini arttırdı. Bu programa başlamadan önce kız öğrencilere gelecekte ne olmak istiyorsun diye sorulduğunda genellikle öğretmen, hemşire, kuaför gibi yanıtlar alındı. Sihirli ellerin tasarımı ödülünü aldıktan sonra meslek seçimi ile ilgili fikirleri değişti. Astronot, drone pilotu, mühendis olmak istediklerini ifade ettiler. Stem uygulamaları, erken yaşlarda uygulandığında öğrencilerin ilgi ve yeteneklerinin keşfedilmesine imkân sağlar. Öğrencilerin küçük yaşlarda ilgi ve yeteneklerini keşfetmesi kariyer planlamasında çok önemlidir. Kendi ilgi ve yeteneklerini bilen öğrenciler eğitim hayatı boyunca eğitimden ne beklediğini ve bunun için yapması gerektiğini bilir. Toplumuzda bilim ve mühendislik ile ilgili mesleklerin hem zor olduğu algısı hem de erkek öğrencileri yönlendirme eğilimi vardır. Bundan dolayı bazı kız öğrenciler hayatları boyunca hiç mühendis olmayı düşünmezler. $\mathrm{Bu}$ programı öğrencilerime uygulamadan önce bile öğrencilerim biz bunu yapamayız, nasıl yapalım, çok zor gibi ifadeler kullandılar. Eğer öğrenciler erken yaşlarda bu uygulamaları okullarda yapar, çalışmalarını başkalarına sunma imkânı verilir ve olumlu geri dönütlerle başarabilirim duygusunu oluşturursa, aile ve toplumuzda oluşan bu tür önyargıların kırılmasını sağlanabilir. Bu nedenle özellikle ilkokullarda STEM uygulamalarının artması önemlidir. Özellikle kız öğrencilerin yükseköğretimde mühendislik alanlarını tercih etmesini sağlamak için, ilkokulda STEM uygulamaları arttırılmalı, ilgi ve yeteneği olan öğrenciler keşfedilip bilim ve mühendislik alanlarına yönlendirilmelidir.

\section{KAYNAK}

Mission Moon Sezonu (2018-2019) Fırst Lego League JR. Takım Çalışma Kılavuzu 